Check for updates

Cite this: RSC Adv., 2017, 7, 27718

Received 2nd May 2017

Accepted 18th May 2017

DOI: $10.1039 / \mathrm{c7ra04921h}$

rsc.li/rsc-advances

\section{Significance of the electron-density of molecular fragments on the properties of manganese(III) $\beta$ - diketonato complexes: an XPS and DFT study}

\begin{abstract}
Roxanne Gostynski, Jeanet Conradie (D) * and Elizabeth Erasmus (D) *
DFT and XPS studies were conducted on a series of nine manganese(III) complexes of the general formula $\left[\mathrm{Mn}(\beta \text {-diketonato })_{3}\right]$, with the ligand $\beta$-diketonato $=$ dipivaloylmethanato (1), acetylacetonato (2), benzoylacetonato (3), dibenzoylmethanato (4), trifluoroacetylacetonato (5), trifluorothenoylacetonato (6), trifluorofuroylacetonato (7), trifluorobenzoylacetonato (8) and hexafluoroacetylacetonato (9). The binding energy position of the main and satellite structures of the $\mathrm{Mn} 2 \mathrm{p}_{3 / 2}$ photoelectron line, as well as the spin-orbit splitting, gave insight into the electronic structure of these manganese(III) complexes. DFT calculations showed that an experimental sample of the $d^{4}\left[\mathrm{Mn}(\beta \text {-diketonato })_{3}\right]$ complex can contain a mixture of different bond stretch isomers and different electronic states, in dynamic equilibrium with one other. The presence of more than one isomer in the experimental sample, as well as interaction between an unpaired $2 \mathrm{p}$ electron (originating after photoemission) and an unpaired $3 \mathrm{~d}$ electron, which aligned anti-parallel to the unpaired $2 p$ electron, caused broadening of the $\mathrm{Mn} 2 \mathrm{p}$ photoelectron lines. Multiplet splitting simulations of these photoelectron lines, similar to those calculated by Gupta and Sen for the free $\mathrm{Mn}(\mathrm{III})$ ion, gave good fits with the observed $M n 2 p_{3 / 2}$ photoelectron lines. The XPS spectra of complexes with unsymmetrical $\beta$-diketonato ligands were simulated with two sets of multiplet splitting peaks, representing both the mer and fac isomers. The satellite structures obtained in both the $M n 2 p_{3 / 2}$ photoelectron line (shake-up peaks) and the ligand F 1s photoelectron line (shake-down peaks), are representative of the ligand-to-metal charge transfer during photoionisation. The binding energies of the $\mathrm{Mn} 2 \mathrm{p}, \mathrm{F}$ 1s and S $2 \mathrm{p}$ electrons, as well as the amount of charge transfer from ligand-to-metal, are both dependent on the electronegativity of the different groups attached to the $\beta$-diketonato ligand.
\end{abstract}

\section{Introduction}

Knowledge of the electronic structure and properties of transition metal complexes is important, due to their role in a variety of chemical and biological processes. High spin manganese(III) complexes have various applications, for example as building blocks in molecular magnets, ${ }^{1-8}$ catalysis, ${ }^{9-14}$ redox mediators in dye-sensitised solar cells, ${ }^{15,16}$ and in biochemical reaction cycles. ${ }^{17-21}$ Due to the four unpaired d electrons of high spin $\mathrm{Mn}$ (III) complexes, their geometry displays the Jahn-Teller effect and also the X-ray photoelectron spectroscopy (XPS) lines of these complexes split into many peaks, due to a coupling interaction between the unpaired core p-electrons (originating after photoemission) and the unpaired valence d-electrons. ${ }^{22}$ Recently an X-ray photoelectron spectroscopy study on $\left[\mathrm{Mn}^{\mathrm{III}}\right.$ (ferrocenyl- $\beta$ diketonato $)_{3}$ ] complexes, where the $\beta$-diketonato ligand contained at least one ferrocenyl group, ${ }^{23}$ showed that a charge-

Department of Chemistry, University of the Free State, PO Box 339, Bloemfontein, 9300, South Africa. E-mail: erasmuse@ufs.ac.za; conradj@ufs.ac.za; Fax: +27-514017295; +27-51-4019656; Tel: +27-51-4019656; +27-51-4012194 transfer process from the $\beta$-diketonato ligand to the $\mathrm{Mn}$ (III) metal centre is responsible for prominent shake-up satellite peaks of the main Mn 2p photoelectron lines. These results further showed that the binding energies of the Mn 2p photoelectron lines are linearly influenced by the sum of the Gordy scale group electronegativities ${ }^{24}$ of the different $\mathrm{R}$ groups attached to the $\beta$-diketonato ligands ( $\mathrm{RCOCHCOFc})^{-}$ ( $\mathrm{Fc}=$ ferrocenyl group), varying over a binding energy range of $0.55 \mathrm{eV}$. By adding the XPS data of $\left[\mathrm{Mn}^{\mathrm{III}}(\beta \text {-diketonato })_{3}\right]$ complexes, where the $\beta$-diketonato ligand does not contain an electron donating ferrocenyl group, we hereby enlarge the range of binding energies of the Mn 2p photoelectron lines by nearly $100 \%$, to a range of $1.07 \mathrm{eV}$. Thus, in continuation of our interest in the geometrical ${ }^{25,26}$ and electronic structure ${ }^{27}$ of $\left[\mathrm{Mn}(\beta \text {-diketonato })_{3}\right] \quad$ complexes containing $\beta$-diketonato ligands with different electrondonating and -withdrawing properties, we hereby present a combined study of theoretical quantum chemistry calculations (using density functional theory, DFT) and experimental measurements (using XPS) on the series of nine non-ferrocene-containing $[\mathrm{Mn}(\beta-$ diketonato $)_{3}$ ] complexes shown in Fig. 1 (with $\beta$-diketonato $=$ dipivaloylmethanato (1), acetylacetonato (2), benzoylacetonato 


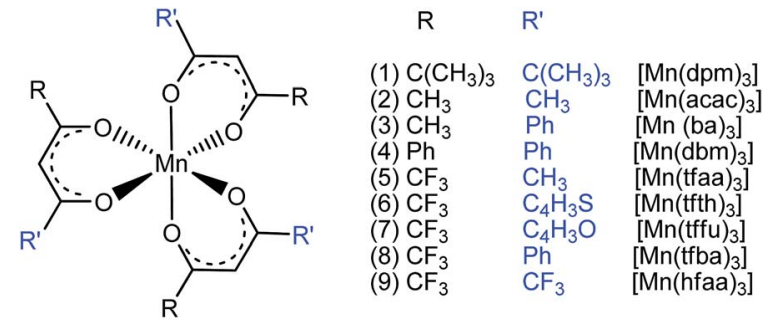

Fig. 1 Structure of the different $\left[\mathrm{Mn}^{\text {III }}(\beta \text {-diketonato })_{3}\right]$ complexes under investigation. The $\beta$-diketonato ligands of complexes 1, 2, 4 and 9 are symmetrical, while complexes $3,5-8$ have unsymmetrically substituted $\beta$-diketonato ligands.

(3), dibenzoylmethanato (4), trifluoroacetylacetonato (5), trifluorothenoylacetonato (6), trifluorofuroylacetonato (7), trifluorobenzoylacetonato (8) and hexafluoroacetylacetonato (9)). Results are also compared with previously published results ${ }^{23}$ on $\left.\left[\mathrm{Mn}^{\mathrm{III}} \text { (ferrocenyl- } \beta \text {-diketonato }\right)_{3}\right]$ complexes.

\section{Results and discussion}

The spectra obtained by X-ray photoelectron spectroscopy (XPS) of $3 \mathrm{~d}$ transition metal complexes containing unpaired $\mathrm{d}$ electrons, frequently contain a variety of several features which arise from the electronic structure of the material. $\left[\mathrm{Mn}(\beta \text {-diketonato })_{3}\right]$ complexes are high-spin paramagnetic octahedral complexes, with a d-electron occupation of $\left(\mathrm{t}_{2 \mathrm{~g}}\right)^{3}\left(\mathrm{e}_{\mathrm{g}}\right)^{1} \cdot{ }^{28}$ Since the electronic configurations $\left(\mathrm{t}_{2 \mathrm{~g}}\right)^{3} \mathrm{~d}_{z^{2}}^{1}$ and $\left(\mathrm{t}_{2 \mathrm{~g}}\right)^{3} \mathrm{~d}_{x^{2}-y^{2}}^{1}$ are degenerate, JahnTeller geometric distortion of $\left[\mathrm{Mn}(\beta \text {-diketonato })_{3}\right]$ complexes occurs in order to remove the degeneracy, with a consequent lowering in symmetry and energy. ${ }^{29}$ Elongation Jahn-Teller distortion in $\left[\mathrm{Mn}(\beta \text {-diketonato })_{3}\right]$ complexes is characterised by two long bonds along the $z$-direction, as well as four short bonds in the $x y$-plane, and a d-electron occupation of $\mathrm{d}_{x y}^{1} \mathrm{~d}_{x z}^{1} \mathrm{~d}_{y z}^{1} \mathrm{~d}_{z^{2}}^{1}$, with the highest occupied molecular orbital (HOMO) of mainly $\mathrm{d}_{z^{2}}$ character. The elongation along the $z$-direction stabilises the energy of the $\mathrm{d}_{z^{2}}$ HOMO. Compression Jahn-Teller distortion in $\left[\mathrm{Mn}(\beta \text {-diketonato })_{3}\right]$ complexes on the other hand, is (a)

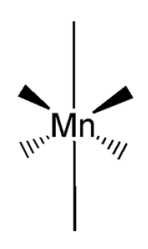

elongation JT

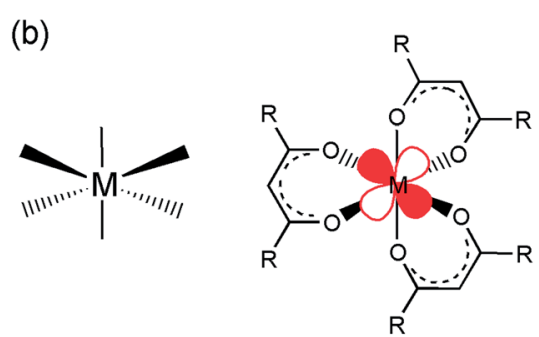

compression JT

(c)

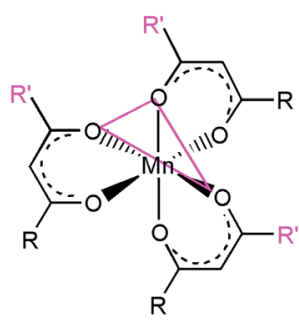

mer

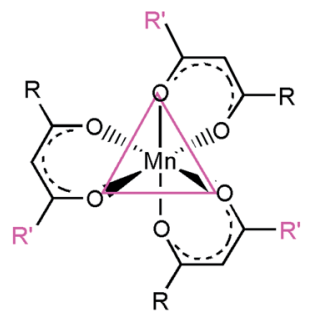

fac

(d)

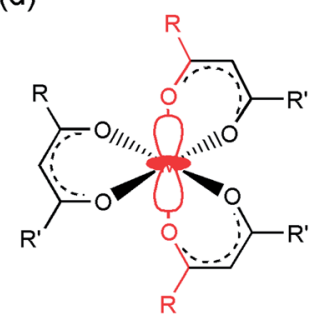

elongation JT mer R-R

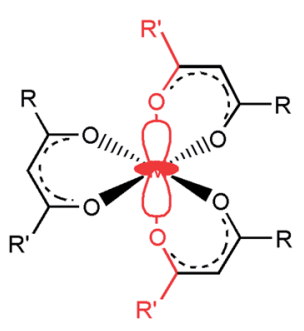

elongation JT mer R'-R'

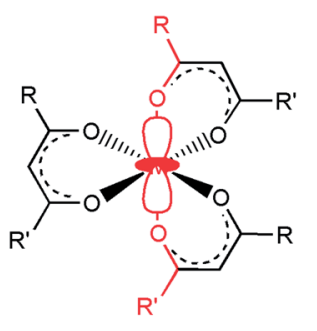

elongation JT mer R-R'

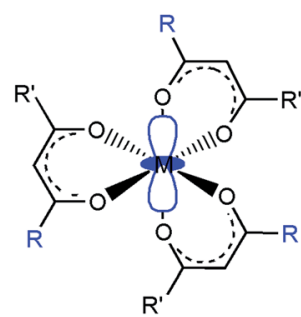

elongation JT fac

Fig. 2 Illustration of the two electronic states of $\left[\mathrm{Mn}(\beta \text {-diketonato })_{3}\right]$ complexes, containing a symmetrical $\beta$-diketonato ligand (RCOCHCOR) , leading to either (a) elongation $\left(d_{x y}^{1} d_{x z}^{1} d_{y z}^{1} d_{z^{2}}^{1}\right)$ or (b) compression $\left(d_{x y}^{1} d_{x z}^{1} d_{y z}^{1} d_{x^{2}-y^{2}}^{1}\right)$ Jahn-Teller distortion. (c) The fac and mer isomers of [Mn( $\beta$ diketonato) $)_{3}$ complexes, containing an unsymmetrical $\beta$-diketonato ligand (RCOCHCOR')- with $\mathrm{R} \neq \mathrm{R}^{\prime}$. (d) Four possible elongation $\left(d_{x y}^{1} d_{x z}^{1} d_{y z}^{1} d_{z^{2}}^{1}\right)$ Jahn-Teller bond stretch isomers for $\left[M n(\beta \text {-diketonato })_{3}\right]$ complexes, containing an unsymmetrical $\beta$-diketonato ligand $(\mathrm{RCOCHCOR})^{-}$with $\mathrm{R} \neq \mathrm{R}^{\prime}$. The $\mathrm{d}_{z^{2}} \mathrm{HOMO}$ or $\mathrm{d}_{x^{2}-y^{2}} \mathrm{HOMO}$ has been superimposed on the structures. 
characterised by two short bonds along the $z$-direction, as well as four long bonds in the $x y$-plane, and a d-electron occupation of $\mathrm{d}_{x y}^{1} \mathrm{~d}_{x z}^{1} \mathrm{~d}_{y z}^{1} \mathrm{~d}_{x^{2}-y^{2}}^{1}$ instead, with the HOMO of mainly $\mathrm{d}_{x^{2}-y^{2}}$ character. Elongation along the $x$ and $y$-directions in this case, stabilises the energy of the $\mathrm{d}_{x^{2}-y^{2}}$ HOMO. ${ }^{25,27}$ The two electronic states $\mathrm{d}_{x y}^{1} \mathrm{~d}_{x z}^{1} \mathrm{~d}_{y z}^{1} \mathrm{~d}_{z^{2}}^{1}$ and $\mathrm{d}_{x y}^{1} \mathrm{~d}_{x z}^{1} \mathrm{~d}_{y z}^{1} \mathrm{~d}_{x^{2}-y^{2}}^{1}$, respectively leading to elongation and compression Jahn-Teller distortion in $[\mathrm{Mn}(\beta-$

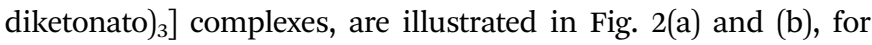
$\left[\mathrm{Mn}(\beta \text {-diketonato })_{3}\right]$ complexes containing a symmetrically substituted $\beta$-diketonato ligand $\left(\mathrm{RCOCHCOR}^{\prime}\right)^{-}$, with groups $\mathrm{R}=\mathrm{R}^{\prime}$.

\subsection{DFT study}

The influence of the ligands upon the geometry, energy and electronic structure of $\left[\mathrm{Mn}(\beta \text {-diketonato })_{3}\right]$ complexes, can conveniently be studied by quantum chemical calculations. DFT calculations conducted on both the two electronic states $\mathrm{d}_{x y}^{1} \mathrm{~d}_{x z}^{1} \mathrm{~d}_{y z}^{1} \mathrm{~d}_{z^{2}}^{1}$ and $\mathrm{d}_{x y}^{1} \mathrm{~d}_{x z}^{1} \mathrm{~d}_{y z}^{1} \mathrm{~d}_{x^{2}-y^{2}}^{1}$ of complexes 1-9, show that for 1-9, the elongation Jahn-Teller distortion geometry is generally more stable than the compression Jahn-Teller distortion geometry, see Table $1 .^{26,30}$ Both elongation ${ }^{31}$ as well as compression Jahn-Teller distortion ${ }^{32,33}$ has experimentally been observed in crystal structures obtained for $\left[\mathrm{Mn}(\beta \text {-diketonato })_{3}\right]$ complexes. However, compression Jahn-Teller distortion as observed for $\left[\mathrm{Mn}(\mathrm{acac})_{3}\right],{ }^{33}$ has actually been attributed to an

Table 1 DFT calculated energies of the indicated electronic states of $\left[\mathrm{Mn}(\beta \text {-diketonato })_{3}\right]$ complexes $1-9$

\begin{tabular}{|c|c|c|c|}
\hline \multirow[b]{2}{*}{ No } & & \multicolumn{2}{|l|}{ Relative energy in eV } \\
\hline & & $\mathrm{d}_{x y}^{1} \mathrm{~d}_{x z}^{1} \mathrm{~d}_{y z}^{1} \mathrm{~d}_{z^{2}}^{1}$ & $\mathrm{~d}_{x y}^{1} \mathrm{~d}_{x z}^{1} \mathrm{~d}_{y z}^{1} \mathrm{~d}_{x^{2}-y^{2}}^{1}$ \\
\hline 1 & {$\left[\mathrm{Mn}(\mathrm{dpm})_{3}\right]^{a}$} & 0.000 & 0.036 \\
\hline 2 & {$\left[\mathrm{Mn}(\mathrm{acac})_{3}\right]^{a}$} & 0.000 & 0.038 \\
\hline 3 & {$\left[\mathrm{Mn}(\mathrm{ba})_{3}\right]^{a}$} & $\begin{array}{l}0.000(\text { mer } \mathrm{Ph}-\mathrm{Ph})^{a} \\
0.015(\text { mer } \mathrm{Ph}-\mathrm{Me})^{a} \\
0.025(\text { mer } \mathrm{Me}-\mathrm{Me})^{a} \\
0.020(\text { fac })^{a}\end{array}$ & $0.056(f a c)^{a}$ \\
\hline 4 & {$\left[\mathrm{Mn}(\mathrm{dbm})_{3}\right]^{a}$} & 0.000 & 0.058 \\
\hline 5 & {$\left[\mathrm{Mn}(\mathrm{tfaa})_{3}\right]$} & $\begin{array}{l}0.000\left(\text { mer } \mathrm{CF}_{3}-\mathrm{CF}_{3}\right) \\
0.030\left(\text { mer } \mathrm{Me}-\mathrm{CF}_{3}\right) \\
0.064(\text { mer } \mathrm{Me}-\mathrm{Me}) \\
0.044(\text { fac })\end{array}$ & $c$ \\
\hline 6 & {$\left[\mathrm{Mn}(\mathrm{tfth})_{3}\right]^{b}$} & $\begin{array}{l}0.000(\text { mer } \mathrm{Th}-\mathrm{Th}) \\
0.016\left(\text { mer } \mathrm{CF}_{3}-\mathrm{CF}_{3}\right) \\
0.025\left(\text { mer } \mathrm{CF}_{3}-\mathrm{Th}\right) \\
0.090(\text { fac })\end{array}$ & $c$ \\
\hline 7 & {$\left[\mathrm{Mn}(\mathrm{tffu})_{3}\right]$} & $\begin{array}{l}0.000\left(\text { mer } \mathrm{CF}_{3}-\mathrm{CF}_{3}\right) \\
0.019\left(\text { mer } \mathrm{CF}_{3}-\mathrm{Fu}\right) \\
0.055(\text { mer } \mathrm{Fu}-\mathrm{Fu}) \\
0.085(\text { fac })\end{array}$ & $c$ \\
\hline 8 & {$\left[\mathrm{Mn}(\mathrm{tfba})_{3}\right]$} & $\begin{array}{l}0.000\left(\text { mer } \mathrm{CF}_{3}-\mathrm{CF}_{3}\right) \\
0.023\left(\text { mer } \mathrm{CF}_{3}-\mathrm{Ph}\right) \\
0.041(\text { mer } \mathrm{Ph}-\mathrm{Ph}) \\
0.071 \text { (fac })\end{array}$ & $c$ \\
\hline 9 & {$\left[\mathrm{Mn}(\mathrm{hfaa})_{3}\right]^{a}$} & 0.000 & 0.037 \\
\hline
\end{tabular}

${ }^{a}$ From ref. 30. ${ }^{b}$ From ref. 26. ${ }^{c}$ Compression Jahn-Teller input geometry spontaneously converged to elongation Jahn-Teller geometry. unusual consequence of unknown crystal packing effects, ${ }^{34}$ stating that typically the tetragonal elongation is the "natural" Jahn-Teller effect of $\left[\mathrm{Mn}(\mathrm{acac})_{3}\right]$, in agreement with the DFT calculations obtained in this study (Hacac $=$ acetylacetone).

When the $\left[\mathrm{Mn}(\beta \text {-diketonato })_{3}\right]$ complex contains an unsymmetrically substituted $\beta$-diketonato ligand (with groups $R \neq R^{\prime}$, as for complexes $\mathbf{3}, \mathbf{5}-\mathbf{8}$ ), then two geometrical isomers are possible, namely both the fac and mer isomers, depending on the arrangement of the unsymmetrical $\beta$-diketonato ligands around the metal; see Fig. 2(c). In the case of unsymmetrical complexes, the elongation Jahn-Teller distortion of the mer isomer can occur along any of the three different $\mathrm{O}_{\beta \text {-diketonato }}{ }^{-}$ $\mathrm{Mn}-\mathrm{O}_{\beta \text {-diketonato' }}$ bonds, leading to as much as three different bond stretch Jahn-Teller elongation mer isomers for the electronic state $\mathrm{d}_{x y}^{1} \mathrm{~d}_{x z}^{1} \mathrm{~d}_{y z}^{1} \mathrm{~d}_{z^{2}}^{1}$, as illustrated in Fig. 2(d). ${ }^{26,30}$ The OLYP/ TZP energies for these four (including the one fac) different elongation $\left[\mathrm{Mn}^{\mathrm{III}}(\beta \text {-diketonato })_{3}\right]$ isomers of unsymmetrical complexes 3, 5-8, are given in Table 1 . The DFT calculations show that for these unsymmetrical complexes $\mathbf{3}, \mathbf{5 - 8}$, (i) the most stable isomer is a mer isomer, (ii) the fac isomer is generally slightly less stable than the different mer isomers, and (iii) the energy differences between the different bond stretch isomers of $\left[\mathrm{Mn}(\beta \text {-diketonato })_{3}\right]$ complexes are small. This result indicates that an experimental sample of $\left[\mathrm{Mn}(\beta \text {-diketonato })_{3}\right]$ can contain a mixture of all four different bond stretch isomers (and possibly also different electronic states), in dynamic equilibrium with one other. This result agrees with the fact that experimental crystal structures of both the $f a c^{15,35}$ and mer isomers $^{\mathbf{2 6}}$ of $\left[\mathrm{Mn}(\beta \text {-diketonato })_{3}\right]$ complexes have been characterised.

While the DFT study focused on the energy and character of the different $\left[\mathrm{Mn}(\beta \text {-diketonato })_{3}\right]$ isomers, which are mainly determined by the valence Mn-d electrons, an X-ray photoelectron spectroscopy (XPS) study of a series of these $[\mathrm{Mn}(\beta$ diketonato $)_{3}$ ] complexes, gave insight into the energies and properties of the core electrons of $\mathrm{Mn}$ and other elements present in $\left[\mathrm{Mn}(\beta \text {-diketonato })_{3}\right]$.

\subsection{XPS study}

$\mathrm{X}$-ray photoelectron spectroscopy (XPS) is a convenient characterisation technique to study the chemical and oxidation states of the elements present in a sample. ${ }^{36}$ The binding energy position, shape and intensity of a photoelectron line can additionally provide a wealth of information regarding the magnetic character, ${ }^{37}$ electronic properties ${ }^{38,39}$ and metal-ligand bond of the elements under investigation. ${ }^{\mathbf{4 0 - 4 2}}$

The XPS of complexes 1-9 in this study all displayed the Mn 2p (641-652 eV), C 1s (ca. $284.5 \mathrm{eV})$ and $\mathrm{O}$ 1s (ca. $528.8 \mathrm{eV}$ ) photoelectron lines, while the XPS of the five fluorine-containing complexes 5-9 also showed the $\mathrm{F}$ 1s photoelectron line (main line at ca. $688.5 \mathrm{eV}$; satellite line at $c a .684 .9 \mathrm{eV}$ ) and complex 6 displayed the $\mathrm{S} 2 \mathrm{p}$ photoelectron lines (main line at ca. $164.7 \mathrm{eV}$; satellite at ca. $161.2 \mathrm{eV}$ ). The Mn 2p region of the XPS spectra of these non-ferrocene containing $\left[\mathrm{Mn}^{\mathrm{III}}(\beta-\right.$ diketonato $)_{3}$ ] complexes 1-9 of this study, is shown in Fig. 3, with selected data tabulated in Table 2. The Mn $2 \mathrm{p}_{3 / 2}$ and $\mathrm{Mn}$ 


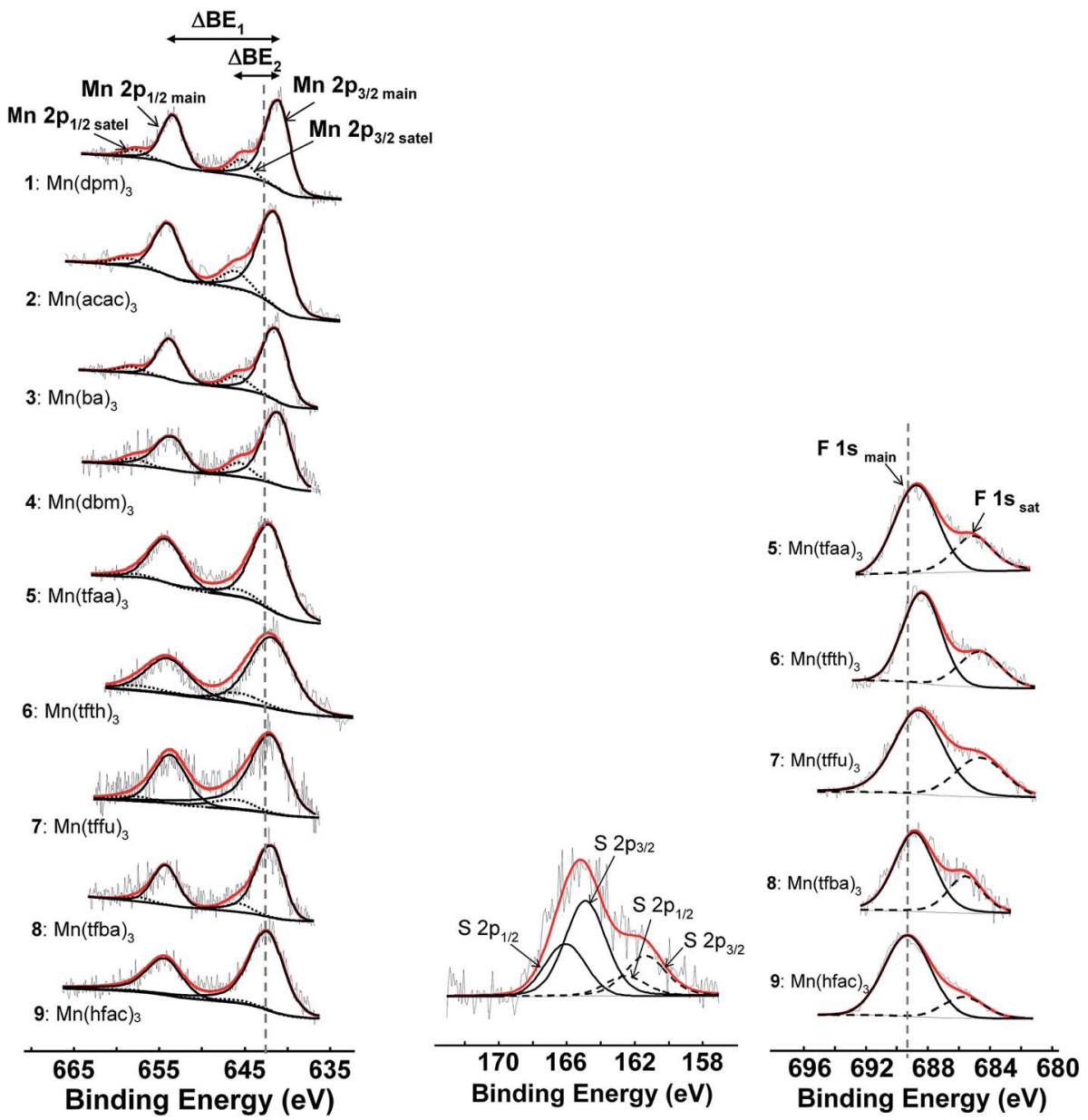

Fig. 3 Comparative XPS spectra, showing one peak fitted for the main and satellite peaks of (left) the Mn $2 p_{3 / 2}$ and $2 p_{1 / 2}$ photoelectron lines, (middle) the S $2 p_{3 / 2}$ and $2 p_{1 / 2}$ photoelectron lines, and (right) the $F$ 1s photoelectron lines of complexes $1-9$. The photoelectron lines are charge corrected against C 1s, at $284.5 \mathrm{eV}$. The grey dashed line at $642.4 \mathrm{eV}$ (left) and $689.3 \mathrm{eV}$ (right), illustrates the shift of the binding energy of complexes 1 to 8 relative to complex 9 .

$2 \mathrm{p}_{1 / 2}$ photoelectron lines are located respectively between $641.67-642.38 \mathrm{eV}$ and $652.82-653.56 \mathrm{eV}$, with the presence of a satellite peak (due to the shake-up mechanism) at a binding energy of $c a .4 \mathrm{eV}$ higher than the main $\mathrm{Mn} 2 \mathrm{p}$ photoelectron lines. The maximum binding energy of the main $\mathrm{Mn} 2 \mathrm{p}_{3 / 2}$ peak of all the $\left[\mathrm{Mn}(\beta \text {-diketonato })_{3}\right]$ complexes 1-9, is found at $c a .3 \mathrm{eV}$ higher than the binding energy of the Mn $2 \mathrm{p}_{3 / 2}$ of the free manganese metal $\mathrm{Mn}^{0}$, which is located at $c a .639 \mathrm{eV} .^{43} \mathrm{This} 3 \mathrm{eV}$ shift to a higher binding energy indicates that $\mathrm{Mn}$ in fact exists in oxidation state III in the complex, which is further confirmed by the $c a .641 \mathrm{eV}$ binding energy reported for other $\mathrm{Mn}^{\text {III }}$ species ${ }^{44}$ as well as by the $641.2 \mathrm{eV}$ previously reported in literature for $\left[\mathrm{Mn}(\mathrm{acac})_{3}\right]$, complex 2, in ref. 45 .

Both the Mn 2 $\mathrm{p}_{3 / 2}$ and $\mathrm{Mn} 2 \mathrm{p}_{1 / 2}$ photoelectron lines exhibit broad peaks, with a fairly high value of $4-6 \mathrm{eV}$ measured for the full width at half maximum (FWHM). The FWHM of the obtained peaks is rather large in comparison with the FWHM of $2.28 \mathrm{eV}$, reported for the Mn $2 \mathrm{p}_{1 / 2}$ photoelectron line of the cubic alloy $\mathrm{Al}_{60} \mathrm{Pd}_{25} \mathrm{Mn}_{15}$, which was measured at a pass energy of $29.5 \mathrm{eV}{ }^{46}$ and in comparison to the $\mathrm{Mn} 2 \mathrm{p}_{1 / 2}$ photoelectron line of elemental $\mathrm{Mn}^{0}$, which gave a FWHM of $2.52 \mathrm{eV}$ (measured at a pass energy of $35.75 \mathrm{eV}) .^{47}$ The unexpectedly high FWHM value observed for these $\mathrm{Mn}^{\mathrm{III}}$ photoelectron lines might be due to various reasons:

(i) $\mathrm{Mn}^{\text {III }}$ is known to exist in a high spin paramagnetic state, ${ }^{48,49}$ and the FWHM of high spin $\mathrm{Mn}^{\mathrm{III}}$ is generally higher than that of a low spin Mn complex. For example, the FWHM of high spin $\mathrm{Mn}^{\text {III }}$ in $\mathrm{Mn}_{2} \mathrm{O}_{3}$ was measured as $1.75 \mathrm{eV}$, while the FWHM of low spin $\mathrm{Mn}^{\mathrm{VI}}$ in $\mathrm{MnO}_{2}$ was found to be only $0.91 \mathrm{eV}$ (both measured at $20 \mathrm{eV}$ pass energy). ${ }^{50}$

(ii) A higher pass energy allows for a larger number of electrons to reach the detector, but the energy determination becomes less precise, causing the FWHM to increase. In this study a large pass energy had to be used in order to obtain well defined peaks (the same pass energy of $93.90 \mathrm{eV}$ was used for all the complexes in the Mn 2p region), which contributed to the higher FWHM. For example, the FWHM of elemental $\mathrm{Mn}^{0}$ is $1.14 \mathrm{eV}$ at $25 \mathrm{eV}$ pass energy, $0.79 \mathrm{eV}$ at $20 \mathrm{eV}$ pass energy and $0.74 \mathrm{eV}$ at $10 \mathrm{eV}$ pass energy, ${ }^{50}$ therefore obtaining smaller FWHM values with decreasing pass energy.

(iii) The larger than expected FWHM value is also an indication of more than one species most probably being present in 
Table 2 Sum of the Gordy scale group electronegativities of all the R-groups, $\Sigma \chi_{R}=3\left(\chi_{R}+\chi_{R^{\prime}}\right)$ of $\left[M n\left(R C O C H C O R^{\prime}\right)_{3}\right]$. The Binding energies at the maximum binding energy ( $\mathrm{BE}$ ) of the $\mathrm{Mn} 2 \mathrm{p}_{3 / 2}$ photoelectron lines, the spin orbit splitting of maximum binding energies of the Mn $2 p$ photoelectron lines $\left(\Delta B E_{1}\right)$, the binding energy of the satellite $M n 2 p_{3 / 2}$ photoelectron line $\left(B E M n 2 p_{3 / 2 \text { sat }}\right)$, as well as the peak separations between main $M n 2 p_{3 / 2}$ and the satellite $M n 2 p_{3 / 2}$ photoelectron lines $\left(\Delta B E_{2}\right)$, the ratio area \% between main $M n 2 p_{3 / 2}$ and the satellite $M n 2 p_{3 / 2}$ photoelectron lines $\left(I_{\text {ratio }}\right)$. The binding energies of the maximum binding energy (BE) of the main and satellite $F 1 s$ photoelectron lines, as well as the ratio area \% between main $\mathrm{F} 1 \mathrm{~s}$ and the satellite $\mathrm{F} 1 \mathrm{~s}$, I ratio

\begin{tabular}{|c|c|c|c|c|c|c|c|c|c|c|c|}
\hline Complex & $\begin{array}{l}\Sigma \chi_{\mathrm{R}}=3 \\
\left(\chi_{\mathrm{R}}+\chi_{\mathrm{R}^{\prime}}\right)^{a}\end{array}$ & $\begin{array}{l}\nu_{\mathrm{CO}} \\
\left(\mathrm{cm}^{-1}\right)\end{array}$ & $\begin{array}{l}\text { BE Mn } \\
2 \mathrm{p}_{3 / 2 \text { main }}(\mathrm{eV})\end{array}$ & $\begin{array}{l}\Delta \mathrm{BE}_{1}{ }^{b} \\
(\mathrm{eV})\end{array}$ & $\begin{array}{l}\text { BE Mn } \\
2 \mathrm{p}_{3 / 2 \mathrm{sat}}(\mathrm{eV})\end{array}$ & $\begin{array}{l}\Delta \mathrm{BE}_{2}{ }^{c} \\
(\mathrm{eV})\end{array}$ & $I_{\text {ratio }}^{d}$ & $\begin{array}{l}\mathrm{BE} \mathrm{Mn} \\
2 \mathrm{p}_{3 / 2 \text { main }} \text { mer }(\mathrm{eV})\end{array}$ & $\begin{array}{l}\text { BE F } \\
1 \mathrm{~s}_{\text {main }}(\mathrm{eV})\end{array}$ & $\begin{array}{l}\text { BE F } \\
1 s_{\text {sat }}(e V)\end{array}$ & $I_{\text {ratio }}{ }^{g}$ \\
\hline$\left[\mathrm{Mn}(\mathrm{dpm})_{3}\right], \mathbf{1}$ & 13.62 & 1591 & 641.67 & 11.88 & 645.87 & 4.20 & 0.16 & 641.49 & $-f$ & $-f$ & $-f$ \\
\hline$\left[\mathrm{Mn}(\mathrm{ba})_{3}\right], 3$ & 13.65 & 1591 & 641.69 & 11.89 & 645.98 & 4.29 & 0.16 & 641.51 & $-^{f}$ & $-^{f}$ & $-^{f}$ \\
\hline$\left[\mathrm{Mn}(\mathrm{dbm})_{3}\right], \mathbf{4}$ & 13.26 & 1592 & 641.67 & 11.80 & 645.99 & 4.32 & 0.17 & $-^{e}$ & $-^{f}$ & $-^{f}$ & $-^{f}$ \\
\hline$\left[\mathrm{Mn}(\mathrm{tfaa})_{3}\right], \mathbf{5}$ & 16.05 & 1598 & 642.05 & 12.21 & 645.81 & 3.76 & 0.11 & 641.87 & 688.49 & 684.88 & 0.41 \\
\hline$\left[\mathrm{Mn}(\mathrm{tfba})_{3}\right], 8$ & 15.66 & 1601 & 641.99 & 12.12 & 645.83 & 3.84 & 0.11 & 641.81 & 688.48 & 684.63 & 0.42 \\
\hline$\left[\mathrm{Mn}(\mathrm{hfac})_{3}\right], 9$ & 18.06 & 1639 & 642.38 & 12.38 & 645.73 & 3.35 & 0.05 & $-^{e}$ & 689.32 & 685.70 & 0.23 \\
\hline
\end{tabular}

the sample, namely the fac as well as different bond stretch mer isomers, as discussed in the previous section.

(iv) The large FWHM value could also be attributed to final state effects, such as the coupling of the angular momenta of the unpaired electrons of the core level after photoionisation, with one of the four unpaired 3d electrons of high-spin $\mathrm{Mn}^{\mathrm{III}}$ of the outer orbitals (causing multiplet splitting), as well as crystal field- and electrostatic interactions. ${ }^{51,52}$ Multiplet splitting is discussed in a separate section below.

2.2.1 Binding energies. The spectral deconvolution of the Mn $2 p_{3 / 2}$ photoelectron lines indicates that complexes 1-9 all display different binding energies $\left(\mathrm{BE}_{\mathrm{Mn} 2 \mathrm{p}_{3 / 2},}\right.$, see Fig. 3 and Table 2), which are influenced by their chemical environment, which in this case are the different groups attached to the $\beta$ diketonato ligands in $\left[\mathrm{Mn}^{\mathrm{III}}(\beta \text {-diketonato })_{3}\right]$ complexes 1-9. It is known that for a fixed oxidation state, the binding energy of a metal-electron increases as the electronegativity of the ligand attached to the metal increases. ${ }^{53}$ For $\beta$-diketones and metal- $\beta$ diketonato complexes, the electronegativity of the $\beta$-diketonato ligands can conveniently be expressed in terms of $\Sigma \chi_{\mathrm{R}}$, which is the sum of the Gordy scale group electronegativities, ${ }^{24}$ of the different $\mathrm{R}$ groups attached to the $\beta$-diketonato ligands $\left(\mathrm{RCOCHCOR}^{\prime}\right)^{-}$. It has been shown that the relative electronwithdrawing or electron-donating ability of different $\mathrm{R}$ groups in $\beta$-diketone ligands as well as metal- $\beta$-diketonato complexes, influences chemical properties like electrochemistry, ${ }^{54,55}$ spectroscopic response, ${ }^{56,57}$ kinetics, ${ }^{58,59}$ turn-over frequency of catalysis, ${ }^{60}$ and NMR peak positions ${ }^{61}$ of the $\beta$-diketone ligands and metal- $\beta$-diketonato compounds. For $\left[\mathrm{Mn}^{\mathrm{III}}\left(\mathrm{RCOCHCOR}^{\prime}\right)_{3}\right]$ complexes, the sum of the Gordy scale group electronegativities is $\Sigma \chi_{R}=3\left(\chi_{R}+\chi_{R^{\prime}}\right)$. Evaluation of the different binding energies of the Mn $2 \mathrm{p}_{3 / 2}$ photoelectron lines of complexes 1-9, shows that the binding energy of the $\mathrm{Mn} 2 \mathrm{p}_{3 / 2}$ electrons increases as $\Sigma \chi_{\mathrm{R}}$ in $\left[\mathrm{Mn}^{\mathrm{III}}\left(\mathrm{RCOCHCOR}^{\prime}\right)_{3}\right]$ increases, see Fig. $4 \mathrm{~A}$. An increase in the electron withdrawing character of the $\beta$-diketonato ligands, expressed as increasing $\Sigma \chi_{\mathrm{R}}$, causes electron density to move away from the manganese metal centre, resulting in a more positive manganese metal centre. The manganese centre therefore binds more strongly to its core electrons, leading to an increase in the binding energy of the $\mathrm{Mn} 2 \mathrm{p}_{3 / 2}$ electrons. ${ }^{60}$ The linear relationship obtained between the binding energy (BE) of the Mn $2 \mathrm{p}_{3 / 2}$ core electrons of complexes 1-9 and $\Sigma \chi_{\mathrm{R}}$, the sum of the electronegativity of the different $\mathrm{R}$ groups in $\left[\mathrm{Mn}^{\mathrm{III}}\left(\mathrm{RCOCHCOR}^{\prime}\right)_{3}\right]$, can be fitted by the following equation (Fig. 4A):

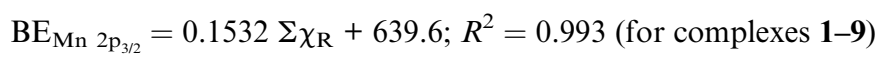

For comparative reasons, data of previously published $\left[\mathrm{Mn}^{\mathrm{III}}(-\right.$ ferrocenyl- $\beta$-diketonato) $)_{3}$ ] complexes, containing an additional $\mathrm{Fe}$ metal, ${ }^{23}$ is also considered at this point. Considering published data $^{23}$ from a previous study of the $\left[\mathrm{Mn}^{\mathrm{III}} \text { (ferrocenyl- } \beta \text {-diketonato }\right)_{3}$ ] complexes 10-14, containing at least one ferrocenyl group on the $\beta$ diketonato ligand (with ligands ferrocenyl- $\beta$-diketonato = $\left(\mathrm{FcCOCHCOCF}_{3}\right)^{-}(\mathbf{1 0}),\left(\mathrm{FcCOCHCOCH}_{3}\right)^{-}(\mathbf{1 1}),(\mathrm{FcCOCHCOPh})^{-}$ (12), $(\mathrm{FcCOCHCOFc})^{-}(\mathbf{1 3})$ as well as (ferrocenyl- $\beta$-diketonato $)_{3}=$ $\left((\mathrm{FcCOCHCOFc})^{-}\right)_{2}\left(\mathrm{FcCOCHCOCH}_{3}\right)^{-}(\mathbf{1 4})$, where $\mathrm{Fc}=$ ferrocenyl), and including this data in the linear fit of $\mathrm{BE}_{\mathrm{Mn} 2 \mathrm{p}_{3 / 2}}$ with $\Sigma \chi_{\mathrm{R}}$, it was found that the above equation stays basically the same, within experimental accuracy (see Fig. 4A), namely:

$\mathrm{BE}_{\mathrm{Mn} 2 \mathrm{p}_{3 / 2}}=0.1503 \Sigma \chi_{\mathrm{R}}+639.6 ; R^{2}=0.995$ (for complexes 1-14)

This result illustrates that the above equation can be used to a high degree of accuracy, to also determine the binding energy of related $\left[\mathrm{Mn}(\beta \text {-diketonato })_{3}\right]$ complexes, if the electronegativity $\chi_{\mathrm{R}}$ of the groups attached to the $\beta$-diketonato ligands $\left(\mathrm{RCOCHCOR}^{\prime}\right)^{-}$, is known. 
2.2.2 Spin-orbit splitting. Another important feature of the Mn 2p XPS peaks, is the difference between the maximum binding energy of the main $2 \mathrm{p}_{3 / 2}$ and $2 \mathrm{p}_{1 / 2}$ peaks, known as the spin-orbit splitting. For complexes 1-9, a spin orbit splitting $\left(\Delta \mathrm{BE}_{1}=\mathrm{BE}_{\mathrm{Mn} 2 \mathrm{p}_{1 / 2 \operatorname{main}}}-\mathrm{BE}_{\mathrm{Mn} 2 \mathrm{p}_{3 / 2 \operatorname{main}}}\right)$ was observed in the range of $\Delta \mathrm{BE}_{1}=11.8-12.4 \mathrm{eV}$. This is in the same order as reported data of $\Delta \mathrm{BE}_{1}=c a .11 .6 \mathrm{eV}$, for $\mathrm{Mn}^{\mathrm{III}}$ in $\mathrm{Mn}_{2} \mathrm{O}_{3} \cdot{ }^{62-64}$

Spin-orbit splitting is an initial state effect, and the magnitude of the separation is dependent on the degree of spin density delocalisation of the electrons in the valence orbitals. ${ }^{6-67}$ Thus it is expected that a more electron withdrawing group (with a higher degree of spin density delocalisation) would be associated with a larger spin-orbit splitting. The correlation between the sum of the Gordy group electronegativities $\left(\Sigma \chi_{\mathrm{R}}\right)$ and the spin-orbit splitting $\left(\Delta \mathrm{BE}_{1}\right)$ between the Mn $2 \mathrm{p}_{3 / 2}$ and Mn 2 $\mathrm{p}_{1 / 2}$ photoelectron lines (see Fig. $4 \mathrm{~B}$ ), is in agreement with the above.

It was found that the spin-orbit splitting $\Delta \mathrm{BE}_{1}$ of the main Mn $2 \mathrm{p}_{3 / 2}$ and $2 \mathrm{p}_{1 / 2}$ peaks for complexes 1-9, increases linearly as $\Sigma \chi_{\mathrm{R}}$ increases (see Fig. $4 \mathrm{~B}$ ):

$$
\begin{gathered}
\Delta \mathrm{BE}_{1}=0.1185 \Sigma \chi_{\mathrm{R}}+10.25 ; R^{2}=0.970 \text { (for complexes 1-9) } \\
\Delta \mathrm{BE}_{1}=0.1110 \Sigma \chi_{\mathrm{R}}+10.36 ; R^{2}=0.972 \text { (for complexes 1-14) }
\end{gathered}
$$

Here again we observe that enlarging the $\Sigma \chi_{\mathrm{R}}$ range, by including Fe-containing ligands from the previous study $^{23}$ of $\left.\left[\mathrm{Mn}^{\mathrm{III}} \text { (ferrocenyl- } \beta \text {-diketonato }\right)_{3}\right]$ complexes $\mathbf{1 0 - 1 4}$ into the linear fit of $\Delta \mathrm{BE}_{1}$ with $\Sigma \chi_{\mathrm{R}}$, does not have any significant influence on the accuracy of the fit or the linear relationship. The presence or absence of the second metal $\mathrm{Fe}$ in the ligand of these $\left.\left[\mathrm{Mn}^{\mathrm{III}} \text { (diketonato }\right)_{3}\right]$ complexes, does not influence the binding energies of the Mn 2p XPS peaks any more than merely the normal effect expected from the electronegativity of the ferrocenyl group.

2.2.3 Shake-up Mn 2p satellite peaks. In addition to the main photoelectron lines displayed by the XPS of complexes containing high-spin metals, satellite structures are often
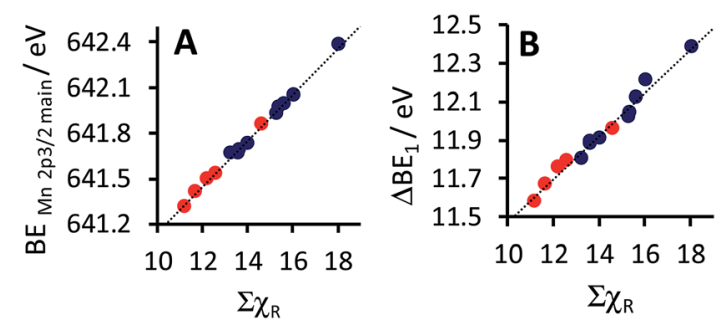

Fig. 4 Relationship between $\Sigma \chi_{R}$, the sum of the Gordy scale group electronegativities of the $\mathrm{R}$-groups on the $\beta$-diketonato ligand of complexes 1-14, with $(A)$ the maximum binding energy $\left(B E_{M n} 2 p_{3 / 2 m a i n}\right)$ of the main $M n 2 p_{3 / 2}$ photoelectron line, as well as with (B) the spin orbit splitting of the maximum binding energy $\left(\Delta B E_{1}\right)$ of the main $M n$ $2 p_{3 / 2}$ and $M n 2 p_{1 / 2}$ photoelectron lines $\left(\Delta B E_{1}=B E_{M n} 2 p_{1 / 2 \text { main }}-\right.$ $\left.B E_{M n ~ 2 p_{3 / 2 m a i n}}\right)$. Data of complexes 1-9 from this study is shown in blue (from Table 2) and data of complexes 10-14 from a previous study in red (from ref. 23). observed. These structures are due to final state effects. They are observed either as shake-up peaks at higher binding energies than the main photoelectron line, or as shake-down peaks at lower binding energies than the main photoelectron line. The position and intensity of these satellite structures both are dependent on the ability of the electron hole that has been created due to photoemission, to be stabilised by the electronic structure of the surrounding environment of the complex. This ability is related to the intrinsic properties of the complex. Published results show that there is a link between the intensity of these shake-up or shake-down satellite peaks and the magnetic moment, $\mu,{ }^{68}$ as well as the spin density of the corresponding complex. ${ }^{69}$

As mentioned earlier and shown in Fig. 3, the $\mathrm{Mn} \mathrm{2p_{3/2 }}$ shake-up satellite peak is located at $c a .4 \mathrm{eV}$ higher binding energy than the main Mn 2 $\mathrm{p}_{3 / 2}$ peak (see also columns 4 and 6 in Table 2). It previously has been shown for paramagnetic $\mathrm{Cu}$ (II) complexes, that the intensity of the satellite peak in comparison

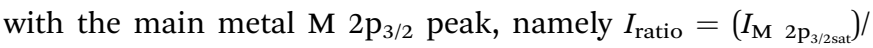
$\left(\begin{array}{ll}I_{\mathrm{M}} & 2 \mathrm{p}_{3 / 2 \mathrm{main}}\end{array}\right)$, increases (non-linearly) as the spin density of the ligands attached to the $\mathrm{Cu}$ metal increases. ${ }^{69}$ In this study it has been found however, that the ratio of the intensity of the satellite peak towards the main $\mathrm{Mn} 2 \mathrm{p}_{3 / 2}$ peak, $I_{\text {ratio }}=$ $\left(I_{\mathrm{Mn} 2 \mathrm{p}_{3 / 2 \text { sat }}}\right) /\left(I_{\mathrm{Mn} 2 \mathrm{p}_{3 / 2 \text { main }}}\right)$, is inversely proportional to $\Sigma \chi_{\mathrm{R}}$, which is a measure of the electronegativity of the different ligands. This "opposite" trend will be explained below.

Satellite peaks are generally caused by one of two phenomena. In the first instance, shake-up peaks commonly observed for paramagnetic transition metals occur, when the kinetic energy of the emitted photoelectron is being reduced due to energy transfer to a non-photoelectron of the same element (causing the non-photoelectron to be in an exited state), which leads to a "shake-up" peak at a higher binding energy than the main line. ${ }^{70}$ On the other hand, shake-up peaks also occur due to a strong configuration interaction in the final state, involving significant ligand-to-metal charge transfer instead (for example in $\mathrm{Ni}(\mathrm{II})$ and $\mathrm{Co}(\mathrm{II})$ ), which results in an "extra" $3 \mathrm{~d}$ electron, compared with the initial state. ${ }^{71}$ The excited energy transfer satellite mechanism in the first instance dominates over the latter charge-transfer satellite mechanism, when firstly the difference between the maximum binding energies of the satellite and the main metal peaks is large (namely the charge transfer energy, $\Delta \mathrm{BE}_{2}$ ), when secondly the core-hole-d-electron Coulomb attraction energy is small, and thirdly when there are many empty $3 \mathrm{~d}$ orbitals. ${ }^{72}$ However, for the $\mathrm{d}^{4}$ complexes 1-9 in this study, with as many as 6 empty $3 \mathrm{~d}$ orbitals each, the observed shake-up peaks can best be interpreted in terms of the latter instance, namely a ligand-to-metal charge transfer during photoionisation, since $\Delta \mathrm{BE}_{2}$ is only a small value (less than $5 \mathrm{eV}$ ). Also, in the F-containing $\left[\mathrm{Mn}^{\mathrm{III}}(\beta \text {-diketonato })_{3}\right]$ complexes 5-9, the corresponding shake-down peaks are observed for the main $\mathrm{F}$ 1s photoelectron line, as well as for the main $S 2 p$ line of the $S$ containing complex 6 (see Section 2.2.4 below). Comparable shake-down satellites were reported in a previous study, for the photoelectron lines associated with the Fe 2 p electrons of the Fecontaining ligand, for related $\left.\left[\mathrm{Mn}^{\mathrm{III}} \text { (ferrocenyl- } \beta \text {-diketonato }\right)_{3}\right]$ complexes. ${ }^{23}$ In addition, the latter charge transfer model also accounts quantitatively for the observed intensities of the 
satellites to the main peaks $\left(I_{\text {ratio }}\right),{ }^{72}$ as was found in this study for complexes 1-9.

The electron configuration of $\mathrm{Mn}$ (III) in complexes 1-9 is $1 s^{2} 2 s^{2} 2 p^{6} 3 s^{2} 3 p^{6} 3 d^{4}$. However, after ligand-to-metal charge transfer during photoionisation of a $2 p$ electron, the final state is $1 \mathrm{~s}^{2} 2 \mathrm{~s}^{2} 2 \mathrm{p}^{5} 3 \mathrm{~s}^{2} 3 \mathrm{p}^{6} 3 \mathrm{~d}^{4+n}$, where $n \approx 1$ denotes the amount of charge transferred from the ligands to the Mn metal. ${ }^{45}$ Ligandto-metal charge transfer during photoionisation, therefore leads to a change in spin density. As more charge is transferred from the ligand to the metal (leading to the "extra" $3 \mathrm{~d}$ electron during photoionisation), the larger the satellite charge transfer peak (shake-up peak) of the metal becomes. The inversely proportional relationship observed between $\Sigma \chi_{\mathrm{R}}$ and $I_{\text {ratio }}$ (Fig. 5B) affirms that $\beta$-diketonato ligands with higher $\Sigma \chi_{\mathrm{R}}$ values (for example $\Sigma \chi_{\mathrm{R}}=18.06$ for complex 9), indicating stronger electron withdrawing properties than others, would obviously transfer less charge to the Mn metal centre during photoionisation of a $2 p$ electron, than the ligands of, for example complex 4 , with a smaller value of $\Sigma \chi_{\mathrm{R}}=13.26$, therefore withdrawing much less electrondensity. In literature, this result also agrees with the linear increase observed for the intensity ratio, $I_{\text {ratio, }}$ with the decrease of the Pauling electronegativity of the halides, ${ }^{73,74}$ for three series of metal-dihalides, namely $\mathrm{CoX}_{2}, \mathrm{FeX}_{2}$ and $\mathrm{MnX}_{2}$, where $\mathrm{X}=\mathrm{F}, \mathrm{Cl}$ or $\mathrm{Br}$. The same increase in $I_{\text {ratio }}$ with decreasing $\Sigma \chi_{\mathrm{R}}$ can be seen in the example of the Mn-dihalides series from literature: $\operatorname{MnF}_{2}\left(I_{\text {ratio }}=0.06, \chi_{\mathrm{F}}\right.$ $=3.98), \mathrm{MnCl}_{2}\left(I_{\text {ratio }}=0.28, \chi_{\mathrm{F}}=3.16\right)$ and $\operatorname{MnBr}_{2}\left(I_{\text {ratio }}=0.38\right.$, $\left.\chi_{\mathrm{F}}=2.96\right) .{ }^{72}$ However, metal-to-ligand charge transfer, as observed for $\mathrm{Cu}(\mathrm{II})$ in literature, ${ }^{69}$ results in the opposite trend between $I_{\text {ratio }}$ and ligand electronegativity (than ligand-to-metal charge transfer) during photoexcitation. The linear relationship obtained between the $I_{\text {ratio }}$ of the Mn $2 \mathrm{p}_{3 / 2}$ peaks and $\Sigma \chi_{\mathrm{R}}$, the sum of the Gordy scale group electronegativities of the R-groups on the ligands, fits the following linear equation (see Fig. 5B):

$$
\begin{gathered}
I_{\text {ratio }}=-0.0256 \Sigma \chi_{\mathrm{R}}+0.5172 ; R^{2}=0.970 \text { (for complexes 1-9) } \\
I_{\text {ratio }}=-0.0248 \Sigma \chi_{\mathrm{R}}+0.5040 ; R^{2}=0.971 \text { (for complexes 1-14) }
\end{gathered}
$$

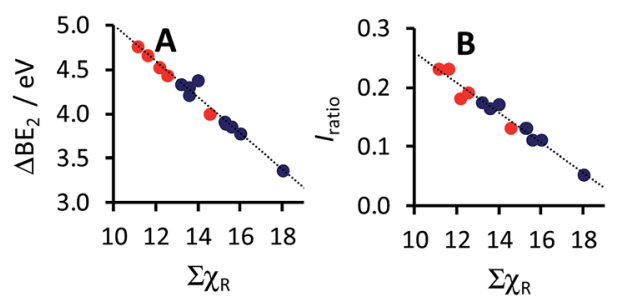

Fig. 5 Relationship between $\Sigma \chi_{R}$, the sum of the Gordy scale group electronegativities of the $\mathrm{R}$-groups on the $\beta$-diketonato ligand, of complexes 1-14, with $(A)$ the charge transfer energy $\left(\Delta B E_{2}\right)$, namely the difference between the maximum binding energy of the main $\mathrm{Mn}$ $2 p_{3 / 2}$ photoelectron line and the satellite $M n 2 p_{3 / 2}$ photoelectron line $\left(\Delta \mathrm{BE}_{2}=B E_{M n ~ 2 p_{3 / 2 s a t}}-B E_{M n ~ 2 p_{3 / 2 m a i n}}\right)$, as well as with $(B)$ the intensity ratio $\left(I_{\text {ratio }}\right)$ of the satellite to the main $M n 2 p_{3 / 2}$ photoelectron lines, $I_{\text {ratio }}=$ $\left(I_{\mathrm{Mn} 2 \mathrm{p}_{3 / 2 \mathrm{sat}}}\right) /\left(I_{\mathrm{Mn} 2 \mathrm{p}_{3 / 2 \mathrm{main}}}\right)$. Data of complexes 1-9 from this study is shown in blue (from Table 2) and data of complexes 10-14 from literature in red (from ref. 23)
2.2.4 Shake-down F 1s and S 2p satellite peaks. Detail of the spectral deconvolution of the $\mathrm{F} 1 \mathrm{~s}$ photoelectron line, present in the XPS of the five $\mathrm{CF}_{3}$-containing complexes 5-9, is shown in Fig. 3. Similarly to the Mn 2p photoelectron lines, the binding energy position of the $\mathrm{F}$ 1s photoelectron line, is also influenced by the sum of the Gordy scale group electronegativities, $\Sigma \chi_{\mathrm{R}}$, of the R-groups attached to the $\beta$-diketonato ligand. Again, (as in Fig. 4A for the main Mn $2 \mathrm{p}_{3 / 2}$ photoelectron line), as the electronegativity of the ligands, $\Sigma \chi_{\mathrm{R}}$, increases, the binding energy $\left(\mathrm{BE}_{\mathrm{F}}\right.$ 1s $)$ of the $\mathrm{F}$ 1s photoelectron line also increases, see Fig. 6A. The linear relationship obtained between the binding energy of the main $\mathrm{F}$ 1s photoelectron line $\left(\mathrm{BE}_{\mathrm{F} 1 \mathrm{~s}_{\text {main }}}\right)$, and the sum of the electronegativity of the different R groups, $\Sigma \chi_{\mathrm{R}}$, of the five fluorine-containing complexes in this study, 5-9, can be fitted by the following linear equation:

$$
\begin{gathered}
\mathrm{BE}_{\mathrm{F} 1 \mathrm{~s}}=0.3834 \Sigma \chi_{\mathrm{R}}+682.39 ; R^{2}=0.979 \text { (for the F-containing } \\
\text { complexes 5-9) }
\end{gathered}
$$

The substructure of the $\mathrm{F}$ 1s photoelectron lines displays a strong shake-down satellite peak, ca. $3.7 \mathrm{eV}$ lower than the main $\mathrm{F}$ 1s photoelectron line. This shake-down peak of the main F 1s photoelectron line is associated with the corresponding shake-up peak of the Mn 2p photoelectron, which depicts the ligand-to-metal charge transfer during photoionisation. The shake-down peak of the $\mathrm{F}$ 1s photoelectron line can be considered representative of some of the charge transfer from the F-containing ligand to the Mn metal.

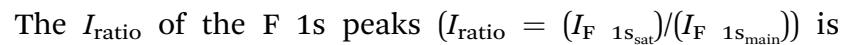
a measure of the amount of charge transferred from the $\mathrm{CF}_{3^{-}}$ containing ligand to the Mn metal of these five complexes 5-9. The intensity ratio, and thus the amount of charge transferred from the fluorine-containing ligand to the Mn metal decreases, as the electronegativity of the $\mathrm{CF}_{3}$-containing ligand $\left(\Sigma \chi_{\mathrm{R}}\right)$ increases (see Fig. 6B). This inversely proportional linear relationship obtained between the $I_{\text {ratio }}$ of the satellite to the main $\mathrm{F}$ 1s peaks with electronegativity $\Sigma \chi_{\mathrm{R}}$, fits the following equation (see Fig. 5B):

$$
\begin{aligned}
I_{\text {ratio }}=-0.0798 \Sigma \chi_{\mathrm{R}}+ & 1.674 ; R^{2}=0.989 \text { (for the F-containing } \\
& \text { complexes 5-9) }
\end{aligned}
$$
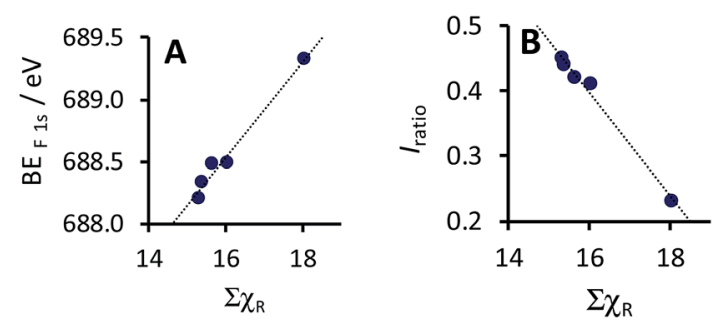

Fig. 6 Relationship between $\Sigma \chi_{R}$, the sum of the Gordy scale group electronegativities of the $\mathrm{R}$-groups on the $\beta$-diketonato ligand, of the five $\mathrm{CF}_{3}$-containing complexes 5-9, with (A) the maximum binding energy $\left(B E_{F} 1 s_{\text {main }}\right)$ of the main $F$ 1s photoelectron line, as well as with (B) the intensity ratio $\left(I_{\text {ratio }}\right)$ of the satellite and main $F$ 1s photoelectron lines, $I_{\text {ratio }}=\left(I_{\mathrm{F}} 1 \mathrm{~s}_{\text {satel }}\right) /\left(I_{\mathrm{F}} 1 \mathrm{~s}_{\text {main }}\right)$. Data from Table 2 . 
The above result implies that the symmetrically substituted ligands in complex $\mathbf{9}$, containing as much as six strongly electron withdrawing $\mathrm{CF}_{3}$ groups, will subsequently transfer even less charge to the Mn metal in complex 9, than in complexes 5-8, which each contain only three electron withdrawing $\mathrm{CF}_{3}$ groups. This observed result agrees with the lowest amount of charge "received" by Mn in complex 9 (Fig. 5B), as given by $I_{\text {ratio }}=$ $\left(I_{\mathrm{Mn} \mathrm{2} \mathrm{p}_{3 / 2 \text { sat }}}\right) /\left(I_{\mathrm{Mn} 2 \mathrm{p}_{3 / 2 \text { main }}}\right)=0.05$ (see the point farthest to the right in Fig. 5B).

The observed ligand-to-metal charge transfer during photoionisation, occurs from the $\beta$-diketonato ligands to $\mathrm{Mn}$. Therefore charge is also transferred from the other atoms on the $\beta$-diketonato ligand to the $\mathrm{Mn}$ metal. For example, in complex 6, containing sulphur in the groups substituted on the ligand, the main S $2 \mathrm{p}_{3 / 2}$ peak at $164.8 \mathrm{eV}$ also exhibits a shake-down charge transfer satellite peak at $161.5 \mathrm{eV}$, with a spin-orbit splitting $\left(\Delta \mathrm{BE}_{1}\right)$ of $3.3 \mathrm{eV}$, as seen in Fig. 3. It however was not possible to also identify the satellite peaks associated with the $\mathrm{C}$ and $\mathrm{O}$ lines in complexes 1-9, due to the presence of adventitious $\mathrm{C}$ and $\mathrm{O}$.

2.2.5 Fitting of fac and mer isomers. As mentioned previously, the large FWHM (full width at half maximum) obtained for the Mn 2p spectral lines, could be an indication that more than one species is present in the sample. The FWHM obtained for the unsymmetrically substituted complexes $\mathbf{3 , 5 - 8}$, for which both fac and mer isomers are possible, is slightly larger (namely 4.9, 5.3, 6.2, 5.1 and $4.7 \mathrm{eV}$ respectively) than the FWHM obtained for complexes 1, 2, 4 and 9 (3.9, 4.4, 4.5 and $5.1 \mathrm{eV}$ respectively), containing symmetrically substituted $\beta$-diketonato ligands. Two peaks, one for the three mer bond stretch isomers and one for the fac isomer, can successfully be fitted into the original Mn 2p peak. The fitting of these simulated peaks into the original Mn 2p peak, results in a much smaller FWHM for the unsymmetrical complexes 3, 5-8 (of 3.8, 4.1, 4.7, 3.9 and $3.6 \mathrm{eV}$ respectively). These fitted values are then comparable to the original FWHM obtained for the symmetrical complexes 1, 2, 4 and 9 (in the range of 3.9-5.1 eV). See Fig. 7, which depicts the fitting of complex 3, as an example of the unsymmetrical complexes. Additionally, the CHI squared value (indicating the goodness of fit) decreased, when two main peaks instead of one were fitted for the unsymmetrical complexes 3, 5-8. For example, for complex 3, CHI squared decreased from 1.6 to 1.5 when fitting two main peaks, thereby accommodating both the fac and the mer isomers. The DFT calculations in Section 2.1.1 above, showed that the fac isomer is generally less stable than the mer isomer, and also that three mer bond stretch isomers are possible for unsymmetrical complexes 3, 5-8. Since the statistical distribution between the three different mer bond stretch isomers and the one fac isomer is $3: 1$, the two Gaussian peaks were fitted in a ratio of $3: 1$ into the original Mn 2p peaks for the unsymmetrical complexes 3, 5-8. The Mn(III) $\beta$-diketonato complexes containing unsymmetrically substituted $\beta$-diketonato ligands $(3,5-8)$, were further simulated to have two Mn main $2 \mathrm{p}_{3 / 2}$ peaks, as well as two satellite peaks; one satellite structure is associated with the three more stable mer bond stretch isomers (at lower energy) and the other satellite peak with the less stable fac isomer (at higher energy). The difference in binding energy between the mer and the fac isomers is $c a .0 .01 \mathrm{eV}$.

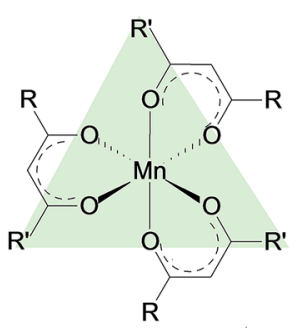

fac isomer

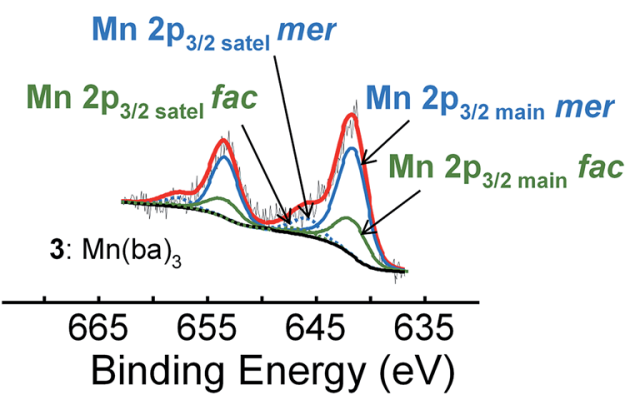

Fig. 7 XPS spectra of the unsymmetrical complex 3 (as a representative), showing the two simulated peaks, as an example for the complexes with unsymmetrical $\beta$-diketonato ligands, representing both the mer and fac isomers (a ratio of $3: 1$ was simulated), as well as the satellite shake-up peaks of the $M n 2 p$ area at a higher binding energy.

The mer and fac simulation of complex 3 is shown in Fig. 7, as an example for the other unsymmetrical complexes.

However, the FWHM obtained above is still larger than expected. A more accurate fitting of the peaks due to additional multiplet splitting, commonly observed in high spin paramagnetic complexes, is therefore needed.

2.2.6 Multiplet splitting. Interaction between an unpaired 2 p electron (originating after photoemission) and an unpaired $3 \mathrm{~d}$ electron, which alignes anti-parallel to the unpaired 2p electron, causes additional splitting of the original Mn 2p photoelectron lines (also contributing to the increased FWHM) of complexes 19. ${ }^{50}$ The photoelectron lines of the Mn 2p presented in this study, are therefore even more complex than described thus far, because of the additional effect of multiplet splitting. ${ }^{75,76}$ Gupta and Sen ${ }^{51,52}$ theoretically calculated the splitting of the $2 p$ peaks of a high-spin free $\mathrm{Mn}^{3+}$ ion, to be in a ratio area percentage of $1: 1: 1.35: 0.7: 0.3$ for the five splitted 2 p peaks. Fig. 8 shows a simulation of the theoretical multiplet splitting ratio as calculated by Gupta and Sen, ${ }^{51,52}$ simulated for both complex 2 (representative of complexes 1, 2, 4 and 9 with symmetric ligands), as well as for complex 3 (representative of complexes 3, 5-8 with unsymmetric ligands, in this case fitting both the fac and mer isomers). These multiplet splitting peaks consist of five components (labelled peaks 1-5 for symmetrical complex 2, as well as f1f5 (fac) and m1-m5 (mer) for the unsymmetrical complex 3). For complex 2, the CHI squared value decreased from 1.8 to 1.3 when multiplet peaks instead of one single peak were fitted for the $\mathrm{Mn}$ $2 \mathrm{p}_{3 / 2}$ photoelectron line, indicating a good fit. The CHI squared value for unsymmetrical complex $\mathbf{3}$, also decreased further from 1.5 (where merely two main peaks for the fac and mer isomers 


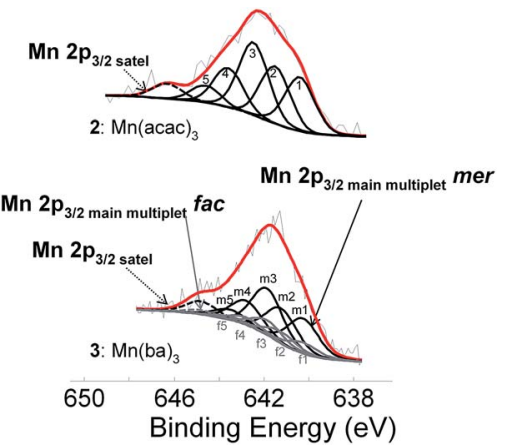

Fig. 8 Detailed $M n 2 p_{3 / 2}$ area of complex 2 (top, showing the simulated multiplet splitting of the symmetrical complex 2), depicting the five components, labelled peaks 1-5; as well as the detailed $M n 2 p_{3 / 2}$ area of complex 3 (bottom, showing the simulated multiplet splitting of the fac (grey line) and the mer (black line) isomers of the unsymmetrical complex 3 ). In the latter complex 3 , the peaks labelled m1-m5 above the spectra belong to the mer isomer, while the five components of the peaks labelled f1-f5 below the spectra, belong to the fac isomer. No multiplet splitting, or separate fac or mer peaks, were fitted to the satellite peak.

were fitted for complex 3) to a CHI squared value of 1.3, when also applying the multiplet splitting peak fitting. The overall FWHM of the Mn $2 \mathrm{p}_{3 / 2}$ photoelectron line when using multiplet splitting, decreased (from the original range of 3.9-6.2 eV, before applying any simulation, see Section 2.2.5) to a range of 1.4-1.8 eV, which is in the same order as was found for related free $\mathrm{Mn}$ ions: For example, the calculated Gupta and Sen multiplet splitting distribution for $\mathrm{Mn}^{2+}$ and $\mathrm{Mn}^{3+}$ free ions, when applied to $\mathrm{Mn}^{2+}$ in $\mathrm{MnO}$, and to $\mathrm{Mn}^{3+}$ in manganite, resulted in FWHM values of the multiplet peaks of 1.7 for $\mathrm{Mn}^{2+}$ and $1.25 \mathrm{eV}$ for $\mathrm{Mn}^{3+},{ }^{77}$ which are similar to the above improved FWHM values for the Mn 2 $\mathrm{p}_{3 / 2}$ peaks (range of 1.4-1.8 eV), after fitting the multiplet splitting.

\section{Experimental section}

\subsection{Synthesis}

A series of nine $\beta$-diketonato manganese(III) complexes of formula $\left[\mathrm{Mn}(\mathrm{RCOCHCOR})_{3}\right]$, with symmetrically substituted groups $\mathrm{R}=\mathrm{C}\left(\mathrm{CH}_{3}\right)_{3}[\mathbf{1}] ;\left(\mathrm{CH}_{3}\right)[2] ;\left(\mathrm{C}_{6} \mathrm{H}_{5}\right)[4]$ and $\left(\mathrm{CF}_{3}\right)[9]$, or of formula $\left[\mathrm{Mn}\left(\mathrm{RCOCHCOR}^{\prime}\right)_{3}\right]$, with unsymmetrically substituted groups $\mathrm{R}=\left(\mathrm{CH}_{3}\right)$ and $\mathrm{R}^{\prime}=\left(\mathrm{C}_{6} \mathrm{H}_{5}\right)[3]$; and also $\mathrm{R}=\left(\mathrm{CF}_{3}\right)$ and $\mathrm{R}^{\prime}$ $=\left(\mathrm{CH}_{3}\right)$ [5], $\left(\mathrm{OC}_{4} \mathrm{H}_{3} \mathrm{~S}\right)$ [6], $\left(\mathrm{OC}_{4} \mathrm{H}_{3} \mathrm{~S}\right)$ [7] or $\left(\mathrm{C}_{6} \mathrm{H}_{5}\right)$ [8], were prepared and characterised according to published methods. ${ }^{78}$

\subsection{XPS measurements}

The X-ray photoelectron spectroscopic (XPS) analysis was carried out with a PHI 5000 Versaprobe, using monochromatic $\mathrm{Al} \mathrm{K} \alpha$ X-ray radiation, with $h \nu=1486.6 \mathrm{eV}$. The hemispherical analyser pass energy, used to record the high resolution spectra, was maintained at $29.35 \mathrm{eV}$ for C 1 s and O 1s, and at $93.90 \mathrm{eV}$ for Mn 2p, S 2p, and F 1s, in order to obtain peaks with good resolution, using $1 \mathrm{eV}$ per step. In order to acquire a neutral charge on the surface of the sample, a low energy electron beam was utilised. All the binding energies of the photoelectron
Table 3 DFT calculated energies of the indicated spin states of $\left[\mathrm{Mn}(\mathrm{acac})_{3}\right]$ optimized with the indicated functionals

\begin{tabular}{|c|c|c|c|c|c|c|}
\hline Spin & BLYP & OLYP & B3LYP & CAM-B3LYP ${ }^{a}$ & $\mathrm{M} 66-\mathrm{D} 3^{a}$ & $\mathrm{M}^{065 \mathrm{X}^{a}}$ \\
\hline 1 & 0.000 & 0.33 & 0.27 & 0.27 & 0.92 & 0.91 \\
\hline 2 & 0.232 & 0.00 & 0.00 & 0.00 & 0.00 & 0.00 \\
\hline
\end{tabular}

spectra were referenced against the lowest binding energy of the C-C simulated adventitious $\mathrm{C}$ 1s photoelectron line, which was set at $284.8 \mathrm{eV}$. The XPS data was analysed, utilising the Multipak version $8.2 \mathrm{c}$ computer software. ${ }^{79}$

\subsection{DFT calculations}

Density functional theory (DFT) calculations were conducted with the ADF (Amsterdam Density Functional) 2013 programme. ${ }^{80}$ The GGA (Generalised Gradient Approximation) functional OLYP (Handy-Cohen and Lee-Yang-Parr), ${ }^{\mathbf{8 1}-\mathbf{8 4}}$ a allelectron TZP (Triple $\zeta$ polarised) basis set, and spin-unrestricted open shell calculations were used for geometry optimisations. The OLYP functional proved to be a good choice for correctly calculating the ground state of high spin 3d metalcomplexes. $^{26,85-89}$ To further support the reliability of the computational method used in this work, the $S=1$ (two unpaired electrons) and $S=2$ (four unpaired electrons) spin states of $\left[\mathrm{Mn}(\mathrm{acac})_{3}\right]$ as representative example of $[\mathrm{Mn}(\beta$ diketonato $)_{3}$ ] complexes, were optimized using a selection of functionals, see Table 3. These results indicate that the OLYP, B3LYP, CAM-B3LYP (B3LYP with long-range correction), M06D3 (M06 with the Grimme empirical dispersion correction) and M065X functionals correctly predicted the experimental high state of $S=2$ of $\left[\mathrm{Mn}(\mathrm{acac})_{3}\right]$, in agreement with experimental EPR studies. ${ }^{28}$

\section{Conclusions}

A DFT study of the energy and character of the Frontier orbitals of $\left[\mathrm{Mn}(\beta \text {-diketonato })_{3}\right]$ complexes shows that a highest occupied molecular orbital (HOMO) of mainly $\mathrm{d}_{z^{2}}$ character is responsible for the elongation of two Mn-ligand bonds along the $z$-direction. $\left[\mathrm{Mn}(\beta \text {-diketonato })_{3}\right]$ complexes containing an unsymmetrically substituted $\beta$-diketonato ligand, can have one fac and three mer bond stretch isomers. An XPS study of the Mn 2p core electron binding energies, provides insight into the influence of the electronic environment caused by the electron donating/withdrawing properties of the $\beta$-diketonato ligands, on the binding energy strength. The main and satellite peaks of the Mn 2p XPS photoelectron lines were fitted with multiplet splitting peaks, as calculated for the free Mn(III) ion by Gupta and Sen, as well as with satellite shake-up peaks, due to charge transfer. Two sets of multiplet splitting peaks, representing the mer and fac isomers, were simulated for the $\mathrm{Mn} 2 \mathrm{p}_{3 / 2}$ photoelectron lines of those $\left[\mathrm{Mn}(\beta \text {-diketonato })_{3}\right]$ complexes containing unsymmetrically substituted $\beta$-diketonato ligands. The relative intensity of the 
satellite peak of both the Mn 2p signal of the metal and the F 1s signal in the five fluorine-containing ligands, is related to the amount of charge transferred between the $\beta$-diketonato ligands and the $\mathrm{Mn}^{\mathrm{III}}$ metal centre.

\section{Acknowledgements}

The authors acknowledge financial support from the South African National Research Foundation and the Central Research Fund of the University of the Free State, Bloemfontein, South Africa. The High Performance Computing facility of the UFS and the Norwegian Supercomputing Program (NOTUR, Grant No. NN4654K) is acknowledged for computer time.

\section{References}

1 (a) M. Viciano-Chumillas, S. Tanase, I. Mutikainen, U. Turpeinen, L. J. de Jongh and J. Reedijk, Inorg. Chem., 2008, 47, 5919; (b) P. Artus, C. Boskovic, J. Yoo, W. E. Streib, L.-C. Brunel, D. N. Hendrickson and G. Christou, Inorg. Chem., 2001, 40, 4199.

2 J. Yoo, A. Yamaguchi, M. Nakano, J. Krzystek, W. E. Streib, L.-C. Brunel, H. Ishimoto, G. Christou and D. N. Hendrickson, Inorg. Chem., 2001, 40, 4604.

3 G. E. Granroth, M. W. Meisel, M. Chaparala, T. Jolicœur, B. H. Ward and D. R. Talham, Phys. Rev. Lett., 1996, 77, 1616.

4 J. S. Miller, C. Vazquez, N. L. Jones, R. S. McLean and A. J. Epstein, J. Mater. Chem., 1995, 5, 707.

5 A. L. Barra, A. Caneschi, D. Gatteschi and R. Sessoli, J. Am. Chem. Soc., 1995, 117, 8855.

6 J. S. Miller, C. Vazquez, J. C. Calabrese, R. S. McLean and A. J. Epstein, Adv. Mater., 1994, 6, 217.

7 J. S. Miller, J. C. Calabrese, R. S. McLean and A. J. Epstein, Adv. Mater., 1992, 4, 498.

8 A. Caneschi, D. Gatteschi, R. Sessoli, A. L. Barra, L. C. Brunel and M. Guillot, J. Am. Chem. Soc., 1991, 113, 5873.

9 (a) R. K. Sodhi and S. Paul, Catal. Lett., 2011, 141, 608; (b) Y.-F. Wang and S. Chiba, J. Am. Chem. Soc., 2009, 131, 12570.

10 R. van Gorkum, E. Bouwman and J. Reedijk, Inorg. Chem., 2004, 43, 2456.

11 R. I. Khusnutdinov, N. A. Shchadneva, A. R. Baiguzina, Y. Y. Lavrentieva and U. M. Dzhemilev, Russ. Chem. Bull., 2002, 51, 2074.

12 (a) J. R. Bryant, J. E. Taves and J. M. Mayer, Inorg. Chem., 2002, 41, 2769; (b) K. A. Campbell, M. R. Lashley, J. K. Wyatt, M. H. Nantz and R. D. Britt, J. Am. Chem. Soc., 2001, 123, 5710.

13 P. Magnus, A. H. Payne, M. J. Waring, D. A. Scott and V. M. Lynch, Tetrahedron Lett., 2000, 41, 9725.

14 M. J. S. Dewar and T. Nakaya, J. Am. Chem. Soc., 1968, 90, 7134.

15 S. Carli, E. Benazzi, L. Casarin, T. Bernardi, V. Bertolasi, R. Argazzi, S. Caramori and C. A. Bignozzi, Phys. Chem. Chem. Phys., 2016, 18, 5949.

16 I. R. Perera, A. Gupta, W. Xiang, T. Daeneke, U. Bach, R. A. Evans, C. A. Ohlin and L. Spiccia, Phys. Chem. Chem. Phys., 2014, 16, 12021.
17 K. A. Campbell, D. A. Force, P. J. Nixon, F. Dole, B. A. Diner and R. D. Britt, J. Am. Chem. Soc., 2000, 122, 3754.

18 R. D. Britt, J. M. Peloquin and K. A. Campbell, Annu. Rev. Biophys. Biomol. Struct., 2000, 29, 463.

19 K. A. Campbell, E. Yikilmaz, C. V. Grant, W. Gregor, A.-F. Miller and R. D. Britt, J. Am. Chem. Soc., 1999, 121, 4714.

20 I. Fridovich, Annu. Rev. Biochem., 1995, 64, 97.

21 K. M. Faulkner, S. I. Liochev and I. Fridovich, J. Biol. Chem., 1994, 269, 23471.

22 E. Paparazzo, J. Electron Spectrosc. Relat. Phenom., 2006, 154, 38.

23 B. E. Buitendach, E. Erasmus, J. W. Niemantsverdriet and J. C. Swarts, Molecules, 2016, 21, 1427.

24 For a comprehensive list of Gordy scale group electronegativities related to $\beta$-diketonato R-groups, see J. Conradie, J. Chem. Soc., Dalton Trans., 2015, 44, 1503.

25 R. Freitag, T. J. Muller and J. Conradie, J. Chem. Crystallogr., 2014, 44, 352.

26 R. Gostynski, P. H. van Rooyen and J. Conradie, J. Mol. Struct., 2016, 1119, 48.

27 R. Freitag and J. Conradie, J. Chem. Educ., 2013, 90, 1692.

28 S. L. Dexheimer, J. W. Gohdes, M. K. Chan, K. S. Hagen, W. H. Armstrong and M. P. Klein, J. Am. Chem. Soc., 1989, 111, 8923.

29 S. Geremia and N. Demitri, J. Chem. Educ., 2005, 82, 460.

30 J. Conradie, Comput. Theor. Chem., 2016, 1087, 1.

31 Cambridge Structural Database (CSD), Version 5.36, May 2015 update. CSD, reference codes: ACACMN21, ACACMN22, ACACMN22, ACACMN23, ACACMN24, JINPIF, JINPIF01, NOSHUA, QAYYEU, XESPIW.

32 P. Magnus, A. H. Payne, M. J. Waring, D. A. Scott and V. Lynch, Tetrahedron Lett., 2000, 41, 9725.

33 J. P. Fackler Jr and A. Avdeef, Inorg. Chem., 1974, 13, 1864.

34 J. Krzystek, G. J. Yeagle, J.-H. Park, M. W. Meisel, R. D. Britt, L.-C. Brunel and J. Telser, Inorg. Chem., 2003, 42, 4610.

35 B. E. Buitendach, E. Erasmus, M. Landman, J. W. Niemantsverdriet and J. C. Swarts, Inorg. Chem., 2016, 55, 1992.

36 J. W. Niemantsverdriet, Microscopy and Imaging, in Spectroscopy in Catalysis: An Introduction, Wiley-VCH Verlag GmbH \& Co. KGaA, 3rd edn, Weinheim, Germany, 2007.

37 I. L. Eremenko, S. E. Nefedov, A. A. Sidorov, M. A. Golubnichaya, P. V. Danilov, V. I. Ikorskii, Y. G. Shvedenkov, V. M. Novotortsev and I. I. Mioseev, Inorg. Chem., 1999, 38, 3764.

38 P. Pfluger and G. B. Street, J. Chem. Phys., 1984, 80, 544.

39 C. Battistoni, J. L. Dormann, D. Fiorani, E. Paparazzo and S. Viticoli, Solid State Commun., 1981, 39, 581.

40 A. E. Bocquet, Phys. Rev. B: Condens. Matter Mater. Phys., 1992, 46, 3771.

41 A. V. Naumkin, T. M. Ivanova, A. V. Shchukarev, A. A. Sidorov, M. A. Kiskin, V. M. Novotortsev and I. L. Eremenko, Russ. J. Inorg. Chem., 2008, 53, 1614.

42 A. E. Bocquet, J. Electron Spectrosc. Relat. Phenom., 1996, 82, 87.

43 V. DiCastro and G. Polzonetti, J. Electron Spectrosc. Relat. Phenom., 1989, 48, 117. 
44 L.-T. Chang, C.-Y. Wang, J. Tang, T. Nie, W. Jiang, C.-P. Chu, S. Aranfin, L. He, M. Afsal, L.-J. Chen and K. L. Wang, Nano Lett., 2014, 14, 1823.

45 A. J. Nelson, J. G. Reynolds and J. W. Roos, J. Vac. Sci. Technol., A, 2000, 18, 1072.

46 C. J. Jenks, S.-L. Chang, J. W. Anderegg, P. A. Thiel and D. W. Lynch, Phys. Rev. B: Condens. Matter Mater. Phys., 1996, 54, 6301.

47 A. R. Chourasia and D. R. Chopra, Surf. Sci. Spectra, 1995, 3, 74.

48 S. Wang, W.-R. He, M. Ferbinteanu, Y.-H. Li and W. Huang, Polyhedron, 2013, 52, 1199.

49 B. J. Kennedy and K. S. Murry, Inorg. Chem., 1985, 24, 1552. 50 M. C. Biesinger, B. P. Payne, A. P. Grosvenor, L. W. M. Lau, A. R. Gerson and R. S. C. Smart, Appl. Surf. Sci., 2011, 257, 2717. 51 R. P. Gupta and S. K. Sen, Phys. Rev. B: Solid State, 1974, 10, 71.

52 R. P. Gupta and S. K. Sen, Phys. Rev. B: Solid State, 1975, 12, 15.

53 J. W. Niemantsverdriet, Spectroscopy in Catalysis, John Wiley \& Sons, $3^{\text {rd }}$ edn, Weinheim, 2007.

54 E. Erasmus, J. Conradie, A. Muller and J. C. Swarts, Inorg. Chim. Acta, 2007, 360, 2277.

55 E. Erasmus and J. C. Swarts, New J. Chem., 2013, 37, 2862.

56 R. Liu, J. Conradie and E. Erasmus, J. Electron Spectrosc. Relat. Phenom., 2016, 206, 46.

57 J. Conradie and E. Erasmus, Polyhedron, 2016, 119, 142.

58 J. J. C. Erasmus and J. Conradie, Dalton Trans., 2013, 42, 8655.

59 M. M. Conradie, J. J. C. Erasmus and J. Conradie, Polyhedron, 2011, 30, 2345.

60 M. M. Conradie, J. Conradie and E. Erasmus, Polyhedron, 2014, 79, 52.

61 A. Kuhn and J. Conradie, Electrochim. Acta, 2010, 56, 257.

62 H. Cao, X. Wu, G. Wang, J. Yin, G. Yin, F. Zhang and J. Liu, J. Phys. Chem. C, 2012, 116, 21109.

63 M. Salavati-Niasari, F. Mohandes, F. Davar and K. Saberyan, Appl. Surf. Sci., 2009, 256, 1476.

64 M. Liu, G.-J. Zhang, Z.-R. Shen, P.-C. Sun, D.-T. Ding and T.-H. Chen, Solid State Sci., 2009, 11, 118.

65 J. C. Carver, G. K. Schweitzer and T. A. Carlson, J. Chem. Phys., 1972, 57, 973.

66 T. M. Ivanova, A. V. Shchukarev, A. V. Naumkin, A. A. Sidorov, M. A. Kiskin, V. M. Novotortsev and I. L. Eremenko, Russ. J. Inorg. Chem., 2008, 53, 1929.

67 E. Agostinelli, C. Battistoni, D. Fiorani, G. Mattogno and M. Nogues, J. Phys. Chem. Solids, 1989, 50, 269.

68 Y. G. Borod'ko, S. I. Vetchinkin, S. L. Zimont, I. N. Ivleva and Y. M. Shul'ga, Chem. Phys. Lett., 1976, 42, 264.

69 M. S. Ioffe and Y. G. Borod'ko, J. Electron Spectrosc. Relat. Phenom., 1977, 11, 235.

70 A. P. Grosvenor, B. A. Kobe, M. C. Biesinger and N. S. McIntyre, Surf. Interface Anal., 2004, 36, 1564.

71 J. S. H. Q. Perera, D. C. Frost and C. A. McDowell, J. Chem. Phys., 1980, 72, 5151.
72 J. Park, S. Ryu, M.-S. Han and S.-J. Oh, Phys. Rev. B: Condens. Matter Mater. Phys., 1988, 37, 10867.

73 L. Pauling, J. Am. Chem. Soc., 1932, 54, 3570.

74 L. Pauling, Nature of the Chemical Bond, Cornell University Press, 1960.

75 E. Ünveren, E. Kemnitz, S. Hutton, A. Lippitz and W. E. S. Unger, Surf. Interface Anal., 2004, 36, 92.

76 A. P. Grosvenor, M. C. Biesinger, R. S. C. Smart and N. S. McIntyre, Surf. Sci., 2006, 600, 1771.

77 H. W. Nesbitt and D. Banerjee, Am. Mineral., 1998, 83, 305. 78 R. Freitag and J. Conradie, Electrochim. Acta, 2015, 158, 418. 79 F. Moulder, W. F. Stickle, P. E. Sobol and K. D. Bomben, Handbook of X-ray Photoelectron Spectroscopy, ULVAC-PHI, Inc., Enzo, Chigasaki, Japan, 1995.

80 G. te Velde, F. M. Bickelhaupt, E. J. Baerends, C. F. Guerra, S. J. A. van Gisbergen, J. G. Snijders and T. Ziegler, J. Comput. Chem., 2001, 22, 931.

81 N. C. Handy and A. J. Cohen, Mol. Phys., 2001, 99, 403.

82 C. Lee, W. Yang and R. G. Parr, Phys. Rev. B: Condens. Matter Mater. Phys., 1998, 37, 785.

83 B. G. Johnson, P. M. W. Gill and J. A. Pople, J. Chem. Phys., 1993, 98, 5612.

84 T. V. Russo, R. L. Martin and P. J. Hay, J. Chem. Phys., 1994, 101, 7729.

85 M. Swart, A. R. Groenhof, A. W. Ehlers and K. Lammertsma, J. Phys. Chem. A, 2004, 108, 5479.

86 J. Conradie and A. Ghosh, J. Phys. Chem. B, 2007, 111, 12621. 87 J. Conradie and A. Ghosh, J. Chem. Theory Comput., 2007, 3, 689.

88 M. M. Conradie and J. Conradie, Electrochim. Acta, 2015, 152, 512.

89 J. Conradie, T. Wondimagegn and A. Ghosh, J. Phys. Chem. B, 2008, 112, 1053.

90 M. J. Frisch, G. W. Trucks, H. B. Schlegel, G. E. Scuseria, M. A. Robb, J. R. Cheeseman, G. Scalmani, V. Barone, B. Mennucci, G. A. Petersson, H. Nakatsuji, M. Caricato, X. Li, H. P. Hratchian, A. F. Izmaylov, J. Bloino, G. Zheng, J. L. Sonnenberg, M. Hada, M. Ehara, K. Toyota, R. Fukuda, J. Hasegawa, M. Ishida, T. Nakajima, Y. Honda, O. Kitao, H. Nakai, T. Vreven, J. A. Montgomery jr, J. E. Peralta, F. Ogliaro, M. Bearpark, J. J. Heyd, E. Brothers, K. N. Kudin, V. N. Staroverov, T. Keith, R. Kobayashi, J. Normand, K. Raghavachari, A. Rendell, J. C. Burant, S. S. Iyengar, J. Tomasi, M. Cossi, N. Rega, J. M. Millam, M. Klene, J. E. Knox, J. B. Cross, V. Bakken, C. Adamo, J. Jaramillo, R. Gomperts, R. E. Stratmann, O. Yazyev, A. J. Austin, R. Cammi, C. Pomelli, J. W. Ochterski, R. L. Martin, K. Morokuma, V. G. Zakrzewski, G. A. Voth, P. Salvador, J. J. Dannenberg, S. Dapprich, A. D. Daniels, O. Farkas, J. B. Foresman, J. V. Ortiz, J. Cioslowski and D. J. Fox, Gaussian 09, Revision D.01, Gaussian Inc., Wallingford CT, 2010. 